\title{
REVESTIMIENTOS APLICABLES SOBRE SOPORTES DE YESO
}

\author{
(COATING APPLICABLE TO GYPSUM ARMATURES)
}

\author{
J. D. Merlet (C.S.T.B.) \\ Traducido y adaptado por: \\ Pablo Diaz Romeral, Arquitecto \\ IETcc/CSIC
}

\section{RESUMEN}

Conocida la sensibilidad al agua del yeso, en el caso de su utilización en muros exteriores, el problema de su protección frente a las solicitaciones es el más importante.

Después de recordar las exigencias (función de impermeabilización, protección de las acciones mecánicas...) y de los principales datos de partida (características de los soportes, datos climáticos y económicos), se aborda un repertorio de soluciones ya experimentadas hasta hoy en Europa y en algunos paises en vias de desarrollo, seguido de un inventario de diferentes posibles soluciones y de los medios de que se dispone para comprobar la aptitud al empleo.

El punto final se refiere a las soluciones que se estudian en la actualidad.

\section{SUMMARY}

Because of its water sensibility the main technical problem of gypsum plaster, for using in external walls, is constituted by its protection against external sollicitations.

After recall of requirements (water tighness in respect of rain water, protection against mechanical actions,...) and of principal basic data (characteristics of supports, climatical and economical data), a list of already used solutions in Europe and Developing countries is made, followed by an inventory of various possible solutions and of the means used in order to verity the workability of these solutions.

In conclusion, the point is doing upon solutions which are emerging.

\section{INTRODUCCION}

El yeso, desde siempre muy utilizado en la construcción en los paises que disponen de él, ha visto, sin embargo -teniendo en cuenta los problemas que plantea su sensibilidad al agua-, limitados prácticamente sus usos, hasta la actualidad, la realización de obras en el interior de los edificios, elementos no portantes, tabiques de distribución y doblado de paramentos, revestimientos, techos, etc.

Parece por tanto interesante investigar otros usos, y principalmente en muros exteriores portantes de yeso, materia prima que en muchos paises en desarrollo está disponible en cantidad apreciable, tanto en la forma de yeso natural como de fosfoyeso, subproducto de la industria quimica todavia poco valorado.

Vista su sensibilidad al agua en el caso de utilización de muros exteriores, el problema de su protección frente a las soluciones exteriores, y fundamentalmente a las climatológicas, importa examinar las soluciones que puedan contemplarse en materia de revestimientos exteriores sobre este tipo de soporte.

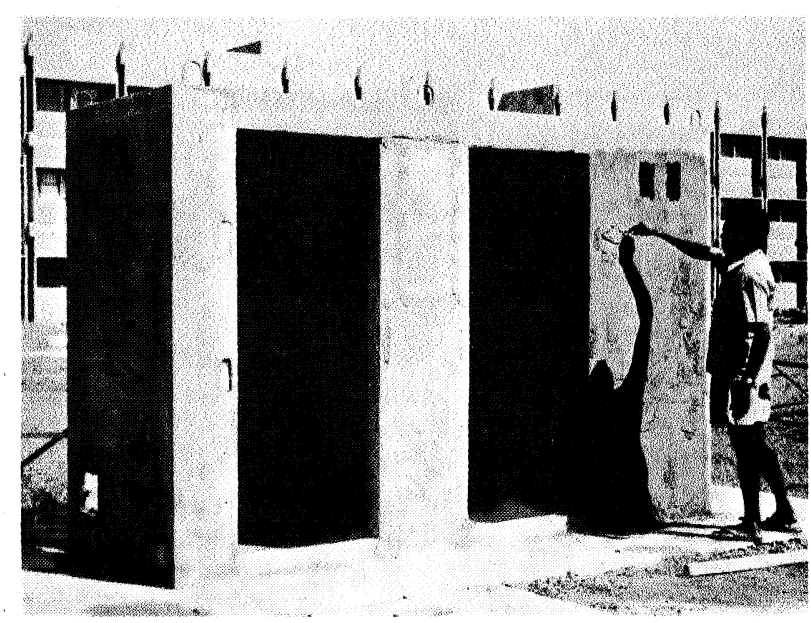

Aplicación manual de un revestimiento de mortero de yeso. 


\section{EXIGENCIAS Y DATOS DE PARTIDA}

\section{Impermeabilización}

El revestimiento debe asegurar la protección frente a la intemperie (lluvia) evitando en el yeso la alteración de sus caracteristicas mecánicas por absorción de agua liquida; por otra parte también participa en la estanquidad de la pared completa. En función de la naturaleza y cualidades del paramento interior, la presencia de humedad en el lado interior, en general no aceptable, puede juzgarse como tolerable según las exigencias de aspecto consideradas como normales en el uso local.

\section{Cualidades de superficie}

Se trata aqui fundamentalmente de la protección frente a las acciones mecánicas (choques, erosión, etc.).

Desde este punto de vista, las calidades intrinsecas del material soporte con base de yeso intervienen con el mismo valor que los usos locales evocados anteriormente, para evaluar el grado de protección que es preciso asegurar.

\section{DURABILIDAD}

Las funciones expuestas deben cumplirse de forma duradera durante un tiempo más o menos largo que puede determinarse caso por caso, en función de la demanda local; la duración debe ser tributaria de las condiciones climáticas del lugar de empleo.

\section{DATOS DE BASE}

\section{Características del soporte}

Las caracteristicas difieren sensiblemente según se trate de yeso celular o en pasta puro e, incluso, en este último caso, de acuerdo con la proporción de mezcla adoptado, incluyendo la naturaleza del yeso en roca del que obtendremos el producto natural, o sintético.

\section{Datos climáticos}

Según los paises en los que se contemple la aplicación de estas soluciones, conlleva que estos datos, fundamentalmente la amplitud de las variaciones térmicas y la pluviometria -importancia de las precipitaciones y duración de èstas, viento, etc...- son sensiblemente diferentes: las solicitaciones resultantes lo serán por consecuencia y las soluciones podrán serlo a diferentes niveles.
Es conveniente tener en cuenta, por ejemplo, la posibilidad de largas secuencias de precipitaciones, pero igualmente la posibilidad de heladas, ver el paso de temperaturas diurnas ampliamente positivas a temperaturas nocturnas negativas con variaciones muy importantes, según las estaciones.

En zona tropical seca, por el contrario, las variaciones de temperatura son más débiles (siempre muy positivas) y poco contrastadas entre estaciones; las precipitaciones pueden ser muy importantes, pero breves, seguidas de periodos de mucho viento con higrometria débil.

\section{Datos económicos}

En función de las soluciones contempladas tanto en el plano de los países considerados como en los tipos de hábitat, conviene tener en cuenta el coste de las soluciones integrando, desde luego, la posibilidad de utilización de materiales locales, o en cualquier caso disponibles localmente si se trata de productos importados.

\section{LOS DATOS DE LA EXPERIENCIA Y LAS DIVERSAS POSIBLES SOLUCIONES. BALANCE DE LAS SOLUCIONES EXPERIMENTADAS HASTA HOY, EN EUROPA, Y LOS PAISES EN VIAS DE DESARROLLO}

\section{Experiencia en Francia}

Los revestimientos de yeso, sobre todo en la región de París, se han empleado ampliamente: se trataba en concreto de mortero de yeso, cal y arena; por otro lado, el hecho de que el diseño de las fachadas (cornisas, impostas, etc.) evitaba que el agua discurriera por los paramentos, estos revestimientos estaban con frecuencia protegidos por la aplicación de pinturas exteriores después de una impregnación endurecida de aceite, que reforzaba e impermeabilizaba la capa superficial del revestimiento, solución que se manifestaba teniendo en cuenta el número de aplicaciones sucesivas, como muy costosa en nuestros dias. Nuevas formulaciones para la reparación de estos "revestimientos a la antigua" han sido objeto de aplicaciones prácticas, siempre en forma de mortero de yeso, cal y arena, a partir de materiales actualmente disponibles en el mercado o especialmente fabricados al efecto (yeso sin adición).

\section{Experiencia en Alemania}

Al final de los años 1960, un sistema de construcción a base de bloques huecos con yeso ha sido empleado en el Sur de Alemania (HOFFMAN). 
Los revestimientos exteriores inicialmente con mortero de cal, revestidos de pintura, han evolucionado hacia morteros bastardos a base de cemento sobresulfatado.

\section{Experiencia en Africa}

Quimicamente se han obtenido bloques de yeso puro, en Senegal, con características mecánicas relativamente elevadas.

Los bloques se han dejado vistos en algunos casos (dispensario) o han sido directamente pintados (fábricas); ensayos de enjalbegado con base de cemento, resinas y cargas, limitados a pequeñas superficies se han realizado también en edificios industriales.

Más recientemente, revestimientos de yeso proyectado al exterior han sido aplicados en edificios de viviendas y oficinas, tanto de yeso puro como con mortero aplicado a la tirolesa.

Estos mismos revestimientos de yeso proyectado se han empleado sobre soportes de bloques de yeso celular.

Experiencia obtenida, en Francia, en el caso de la puesta a punto de las técnicas de reparación de revestimiento de yeso proyectado al exterior que se habian degradado

Una de las causas iniciales de los desórdenes constatados es con frecuencia una fisuración de la albañilería, que se prolonga al revestimiento y es una causa de penetración del agua, o de acumulación de ésta en el soporte, disolución del revestimiento en la interfase, debilitamiento de esta zona y decohesión progresiva.

En el caso de soporte en yeso, si hay riesgo de penetración de agua que pueda quedar atrapada, conviene proporcionar la posibilidad de recuperar el agua detrás del revestimiento, por ejemplo mediante un revestimiento de tipo membrana.

En otras clases de desórdenes, destaca la importancia de la exposición particularmente desfavorable de determinadas partes de obra: asientos diferenciales, apoyos en vanos, cimentaciones, etc.; se encuentran, desde luego, problemas análogos con las piedras (calcáreas, sobre todo): en este caso se han experimentado tratamientos hidrófugos de superficie (impregnación por capilaridad); la eficacia del tratamiento está en función de las caracteristicas del soporte (porosidad e incluso dimensión de los poros) al que el producto debe adaptarse (viscosidad fundamentalmente, número de capas,...).

\section{INVENTARIO DE LAS DIVERSAS PISTAS DE SOLUCION Y VERIFICACION DE LA APTITUD AL EMPLEO}

Las soluciones contempladas difieren básicamente:

- Por la naturaleza de los materiales constitutivos del revestimiento.

- Por la concepción propiamente dicha del revestimiento: aplicación directa adherida o no solidario (revestimiento del tipo membrana) con o sin cámara de aire intermedia.

Entre los revestimientos adheridos, la compatibilidad con el yeso soporte conduce a retener, en mayor medida que los morteros bastardos, cemento y cal, morteros con base de yeso y cal, tales como el empleado actualmente para la ejecución de los «revestimientos de yeso» en la región de Paris: éste se compone, en función de las caracteristicas de sus componentes (arena fina $0 / 1,6$, cal aérea y yeso grueso sin adición), en la proporción de 3 volúmenes de yeso por un volumen de cal y dos de arena.

Los revestimientos adheridos de tipo orgánico armados están constituidos por:

- Un fijador de fondo con función primaria de adherencia.

- Un revestimiento de base, armado, aplicado en dos manos por encolado de la armadura (velo de vidrio no tejido... entre las dos manos).

Este revestimiento de base, orgánico, es también de naturaleza de yeso.

\section{Una capa de acabado}

La utilización de mortero de cemento puede ser posible según la técnica similar de los "revestimientos membrana", interponiendo entre soporte de yeso y mortero una pantalla que, a la vez, resuelve el problema de una eventual incompatibilidad, asegura la regularidad de espesor del mortero aplicado y conserva en este último la cantidad de agua necesaria para su fraguado evitando su succión prematura por el soporte.

La aptitud al empleo se aprecia mediante ensayos de comportamiento global en maquetas, con las dimensiones de un muro, permitiendo someter al conjunto a ciclos de envejecimiento artificial y básicamente a variaciones de temperatura de amplitud variable (revestimiento - membrana con mortero armado, con una malla y revestimientos orgánicos armados). Para los morteros de cal y yeso, ensayos orientativos se han llevado a cabo sobre maquetas de dimensiones menores $(0,60 \times 0,60 \mathrm{~m})$ incluyendo juntas, de acuerdo con las modalidades para los revestimientos de impermeabilización con mortero de ligantes hidráulicos. 
Sobre el soporte de yeso celular, que se caracteriza por sus propiedades mecánicas modestas, ha sido objeto de ensayos y aplicaciones de diferentes soluciones:

* Revestimientos adheridos:

- revestimiento de yeso proyectado al exterior en pasta pura de un módulo relativamente elevado: este revestimiento provoca, para fuertes amplitudes de variación de temperatura, un cizallamiento del soporte en la masa, en la parte posterior de la interfase revestimiento-soporte; los ensayos de orientación realizados con morteros de yeso y cal conducen a la misma conclusión;

- sistemas de ligante orgánico armados, puestos en obra después de la aplicación de una impresión endurecedora: se constata el final de los ciclos de envejecimiento artificial un pelado del conjunto; la capa "endurecida", a falta de una penetración suficiente del tratamiento previo, queda a nivel superficial; el refuerzo mecánico carece de eficacia al punzonamiento cualquiera que sea el sistema de armadura ensayado (tela de vidrio, no tejida...);

- sistemas sin solidarización, del tipo revestimiento-membrna: es la solución que se ha aplicado en Rennes y continúa en servicio después de dos años en forma satisfactoria.

Otra solución ha sido objeto de experimentación en laboratorio. Se distingue de la procedente por el uso de una armadura adaptada que permite a su "centrado" en la masa del revestimiento y la interposición, entre soporte y mortero, de una pantalla, suprimiendo la cámara de aire existente en la solución precedente.

\section{Es necesario precisar a este respecto:}

- fijaciones de la armadura teniendo en cuenta las caracteristicas del soporte: número y separación de los puntos de fijación;

- conservación en el tiempo de la armadura metálica, teniendo en cuenta el débil espesor del recubrimiento y de la ausencia de "ventilación» en la cara posterior;
- evaluación del fraccionamiento necesario para paliar las consecuencias de los movimientos diferenciales, fundamentalmente en las uniones con los vanos (refuerzos en diagonal) (uniones flexibles...): separación de juntas considerando el dimensionamiento de la armadura (sección de acero relativamente importante) y de su posición en el revestimiento, lo que conduce a priori a una mayor eficacia.

Sobre el soporte de yeso puro, cuyas cualidades mecánicas son más favorables, los mismos revestimientos han sido objeto igualmente de ensayos y aplicaciones, pero el acento se ha puesto sobre los revestimientos adheridos y fundamentalmente sobre los morteros de yeso y cal: la fórmula (yeso 3, arena 2, cal 1) presenta características elevadas y diferentes formulaciones se han ensayado disminuyendo el contenido de ligante para aproximar estas características a las del yeso soporte.

La formula (Y2, A3, C1) ha sido desechada. Más allá se plantean problemas de adherencia al soporte e incluso de aplicación práctica (el mortero es muy dificil de trabajar).

\section{CONCLUSIONES}

El resultado de la experiencia muestra que los revestimientos adheridos parecen prácticamente útiles sobre soporte de yeso celular.

Para el soporte de yeso puro, que es más favorable, la solución mortero de yeso y cal aparece como la más prometedora, incluso si la formulación debe adaptarse progresivamente en función de los elementos constitutivos disponibles en el lugar. Las soluciones de revestimientos armados, técnicamente admisibles, serian, por el contrario, de aplicación más compleja y de un coste sensiblemente superior (doble o triple). Por fin, conviene no perder de vista que la obra debe considerarse globalmente; en las condiciones climáticas favorables (caso de clima tropical seco), el aspecto estará en función de que se garantice la impermeabilización por un lado, y por otro, que las solicitaciones, sobre todo bajo la acción de las variaciones de temperatura, puedan reducirse sensiblemente. 